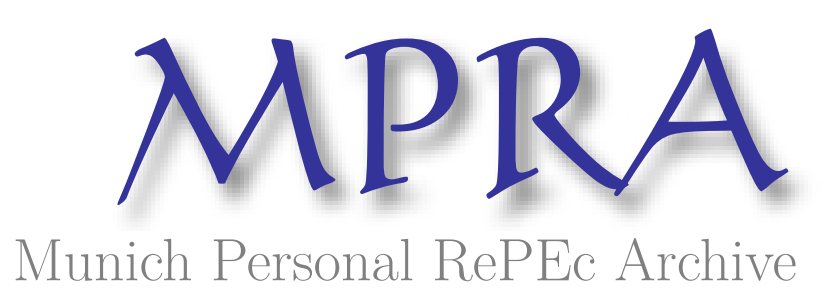

Behavioral economics and socio-economics journals: A citation-based ranking

Azar, Ofer H.

Ben-Gurion University of the Negev

2006

Online at https://mpra.ub.uni-muenchen.de/4377/

MPRA Paper No. 4377, posted 07 Aug 2007 UTC 
This is a pre-print working paper version (before the review process), of the article Azar, Ofer H. (2007), "Behavioral Economics and Socio-Economics Journals: A CitationBased Ranking," Journal of Socio-Economics, 36(3), 451-462.

The final version of this article (that is significantly different from this version) is available at http://dx.doi.org/10.1016/j.socec.2006.11.001.

\title{
Behavioral Economics and Socio-Economics Journals: A Citation-Based Ranking
}

\author{
Ofer H. Azar \\ Department of Business Administration \\ Guilford Glazer School of Business and Management \\ Ben-Gurion University of the Negev, Israel
}

Journal quality is a major consideration for authors, readers, and promotion and tenure committees, among others. Unfortunately, most behavioral economics and socio-economics journals are not included in published rankings or in Journal Citation Reports. Consequently, no objective ranking of these journals exists. To address this need, a list of journals in behavioral economics and socio-economics was compiled, and the number of articles that cited each journal was recorded for the periods 2001-2005, 1996-2000, and 1996-2005. In all periods Journal of Economic Behavior \& Organization was ranked first and Journal of Economic Psychology second. In 2001-2005 Journal of Socio-Economics ranked third.

Keywords: Journal rankings; Citation analysis; Behavioral economics; Socio-economics; Economics and psychology

JEL classification codes: A14, A12, A10, B50, Z10, Y80

* Ofer H. Azar, Department of Business Administration, School of Management, Ben-Gurion University of the Negev, P.O.B. 653, Beer Sheva 84105, Israel. Tel.: +972-8-6472675; Fax: +972-8-6477691. E-mail address: azar@som.bgu.ac.il. 


\section{Introduction}

One of the fundamental working hypotheses in academia is that there is a strong positive correlation between the quality of an article and the quality of the journal in which it is published. Indeed, a journal attains high quality and reputation by publishing good articles, leading to this positive correlation. As a result, knowing the quality of the journal is of great importance to many people in academia: authors want to know this in order to choose smartly to which journals to submit their papers; readers want to know the journal's quality in order to decide which articles deserve careful reading; and promotion and tenure committees, as well as funding agencies and people who write reference letters, need to know the journal's quality in order to assess correctly the qualifications of a candidate for promotion, tenure, or a grant. Journal quality is also the basis for many rankings of universities and departments - in order to estimate the academic value of each publication generated by the department's faculty, for example, the quality of the journal in which the article was published has to be taken into account (see for example Coupe, 2003 and Lubrano et al., 2003).

The most common way to assess the quality of journals is based on the number of citations they receive. ${ }^{1}$ When an article is cited, it generally suggests that it contributed significantly to the literature on which the citing article builds, and so the number of citations that an article receives is a commonly-used indication of its quality. When we add up the number of citations that all the articles published by a certain journal received, we obtain a measure of journal quality.

\footnotetext{
${ }^{1}$ Sometimes further manipulations are used, such as giving different weights to different citing journals, or dividing the number of citations received by the number of pages or articles in the journal.
} 
The importance of citations in indicating journal quality led to the creation of various databases that record citations in academic journals. ISI Web of Knowledge (henceforth ISI) and its "Web of Science" database, for example, include Science Citation Index Expanded, Social Sciences Citation Index, and Arts \& Humanities Citation Index. These databases track continuously thousands of journals in various disciplines and record all the citations that appeared in them. Based on these databases, ISI also publishes its "Journal Citation Reports" (henceforth JCR) that report the total number of citations that a journal received in a given year from all other journals in the database, as well as some additional measures of journal performance.

The great importance of assessing the relative quality of journals resulted in various rankings of academic journals. In economics, for example, some prominent examples include the rankings by Liebowitz and Palmer (1984), Laband and Piette (1994), and Kalaitzidakis et al. (2003). Additional economics journal rankings include Barrett et al. (2000), who created rankings by sub-discipline (according to JEL codes) ${ }^{2}$, the perception-based ranking by Axarloglou and Theoharakis (2003), and the ranking based on citations in textbooks by Liner (2002).

In principle, one can learn from a general ranking also about the relative position of journals in a certain sub-field. In practice, however, these general rankings often do not include enough of the sub-field journals to provide meaningful information for people interested in that specific sub-field. As a result, rankings of journals in a specific sub-field are sometimes published to address this need, for example the agricultural economics ranking by

\footnotetext{
${ }^{2}$ They ranked the journals that contributed the most to each JEL letter category (e.g., code L is industrial organization). Unfortunately, no letter corresponds to behavioral economics or socio-economics, so their rankings are not helpful to researchers in these areas.
} 
Burton and Phimister (1996), the applied econometrics ranking by Baltagi (1999), and the international business ranking by Dubois and Reeb (2000).

Unfortunately, in behavioral economics and socio-economics the vast majority of journals are not included in published rankings of economics journals or in the JCR data, and yet no journal ranking for these fields was published yet. Consequently, there is no objective measure of journal quality for most journals in these fields. This article attempts to address this lack by providing such a ranking.

Behavioral economics encompasses these areas that are related to both economics and psychology, for example the effect of psychological motivations on economic decision making and consequently also on firms and markets. Socio-economics includes areas that are related to both economics and sociology, for example the influence of social norms on economic behavior. It makes sense to include both behavioral economics and socioeconomics journals in the same ranking because the overlap between these two fields is large. The effect of social norms on economic behavior, for example, is often related also to psychological motivations and to social psychology. This large overlap between behavioral economics and socio-economics is also reflected in the relevant journals, with many journals publishing research in both areas.

\section{Methodology}

The first step in creating a ranking of behavioral economics and socio-economics journals is to decide which journals belong to this group. To do so, the databases of ISI and Ulrich's Periodicals Directory (henceforth UPD) were searched, and journals that satisfied the conditions of being active, refereed, academic / scholarly, published more than once a year, and in English, were considered. The journal descriptions in UPD, the information provided on the journals' websites (e.g., the aims and scope of the journal), and the journals' articles 
were used in order to determine which journals focus on behavioral economics and/or socioeconomics and should therefore be included in the ranking. Table 1 presents the journals selected and some information about them (based on UPD data).

In order to rank the journals, the database of ISI was used. This database tracks only a selection of journals, which does not include most of the journals listed in Table 1. Fortunately, however, ISI database is nevertheless useful, because it records all citations from the indexed journals, even when the cited journal is not an indexed journal. This allows to use ISI database to obtain citation information even for journals that ISI does not index. It should be emphasized that the citations recorded in this database are therefore not all the citations that a certain article received, but those that came from journals indexed by ISI.

Rankings of academic journals often follow one of two alternative methodologies. One is to compute the total number of citations the journal received, and the second is to compute a per-article measure of citations by dividing the total number of citations by the number of articles in the journal (this is often called an "impact factor"). Here I follow the first methodology, for two reasons.

First, the goal here is to evaluate the importance of journals and their contribution to research in behavioral economics and socio-economics. It is clear that a journal that publishes 100 articles each year and generates 1000 citations is much more influential and important, and contributes more to research in the field, than a journal that publishes 20 articles each year and generates 200 citations, even though the impact factor is identical for both journals.

Second, when we compare rankings obtained using the two alternative measures, it becomes clear that the first methodology produces more reasonable results. For example, Table 2 presents the top 10 journals in JCR economics for 2004 based on either the total number of citations they received or their impact factor. It is easy to see from the table that 
the ranking based on total citations reflects the most important and respected journals in economics much better than the ranking based on the impact factor.

Because most of the journals listed in Table 1 are not indexed by ISI, we cannot use JCR to obtain information on the number of times they were cited. It is possible, however, to get a closely related measure of citations using manual searches in the ISI database and filtering the results. ${ }^{3}$ What we can obtain this way is the number of different articles that cited a certain journal in a certain time period. This method was employed over a recent time period (2001-2005), an earlier period (1996-2000), and a combined period (1996-2005). The period 2001-2005 gives the most updated information and best represents the current quality of the listed journals, especially given that several journals started during the period 1996-2000. The period 1996-2000, however, allows to examine which journals moved up or down over the last decade, and how stable is the ranking over time. The combined period gives information that is based on a longer period and therefore reflects the quality of the journals over a longer time period.

\section{Results}

Table 3 presents the rankings obtained from the methodology explained above in the three periods. The results show that the Journal of Economic Behavior \& Organization is by

\footnotetext{
${ }^{3}$ ISI uses various shorthands to record the names of journals, and not always in a consistent manner for journals that are not indexed. For example, the Journal of Socio-Economics appears as J SOCIOECONOMICS, J SOCIO EC, J SOCIOECON, and in a few cases even in other forms. Therefore, in order to get all the citations to a journal, one needs to search for all possible ways it could be indexed and to use wildcards in the search for this purpose, and then go over the results one by one to make sure no other journals are included (for example, searching for the Journal of Socio-Economics using "J socio*ec*" also gives results like J SOCIO EC DEV, which should be discarded).
} 
far the most-cited journal, for any of the three periods. The second place goes in all periods to the Journal of Economic Psychology. The third place goes in 2001-2005 to the Journal of Socio-Economics, which made a big jump up from 1996-2000 to 2001-2005. ${ }^{4}$ The journal that occupied the third place in 1996-2000 but lost this position to be ranked 4.5 in 20012005 is Rationality and Society. Other than the Journal of Socio-Economics and Rationality and Society, no other journal in the top 8 journals moved more than one rank between the two periods.

In order to be able to compare the performance of the journals in the list not just among themselves but also to journals in other disciplines, the number of citing articles for the period 2001-2005 was computed also for several journals from other disciplines that might be of interest to those who work in the fields of behavioral economics and socio-economics, such as economics, psychology, marketing, consumer behavior, and sociology. It should be noted, however, that one should take into account that some disciplines tend to cite more than others. For example, if we take the total number of citations received by all journals in a discipline in 2004 and divide it by the number of articles published in that discipline, we get 19.8 in economics, 20.4 in sociology, 24.1 in applied psychology, and 25.4 in business. When comparing between disciplines these differences should be considered. An applied psychology journal that was cited in 300 articles, for example, might in fact be in a lower relative ranking (in the applied psychology field) compared to the relative ranking in economics of an economics journal that was cited in 270 articles.

\footnotetext{
${ }^{4}$ Two main changes can help explain this big jump in JSE ranking: in 2002 the editor of the JSE and much of the editorial board changed, and at around the same time Elsevier purchased the journal - and big publishers such as Elsevier often make journals more easily accessible, thus helping to disseminate the journal's articles, which can result in them being cited more often.
} 


\section{Conclusion}

This article reports for the first time a ranking of journals in the fields of behavioral economics and socio-economics. This is an important endeavor because it gives valuable information to people who want to evaluate the quality of different journals in this area, such as authors, readers, and members of promotion and tenure committees.

\section{References}

Axarloglou, K., Theoharakis, V., 2003. Diversity in economics: An analysis of journal quality perceptions. Journal of the European Economic Association 1, 1402-1423.

Baltagi, B., 1999. Applied econometrics rankings: 1989-1995. Journal of Applied Econometrics 14, 423-441.

Burton, M., Phimister, E., 1996. The ranking of agricultural economics journals. Journal of Agricultural Economics 47, 109-114

Barrett, C.B., Olia, A., Bailey, D.V., 2000. Subdiscipline-specific journal rankings: whither Applied Economics? Applied Economics 32, 239-252.

Coupe, T., 2003. Revealed performances: world wide rankings of economists and economic departments: 1990-2000. Journal of the European Economic Association 1, 1309-1345.

Dubois, F.L., Reeb, D., 2000. Ranking the International Business Journals. Journal of International Business Studies 31, 689-704.

ISI Web of Knowledge: Web of Science and Journal Citation Reports databases, available online at http://portal.isiknowledge.com/

Kalaitzidakis, P., Mamuneas, T., Stengos, T., 2003. Rankings of academic journals and institutions in economics. Journal of the European Economic Association 1, 1346-1366.

Laband, D., Piette, M., 1994. The relative impact of economics journals. Journal of Economic Literature 32, 640-666. 
Liebowitz, S.J., Palmer, J.P., 1984. Assessing the relative impacts of economic journals. Journal of Economic Literature 22, 77-88.

Liner, G.H., 2002. Core journals in economics. Economic Inquiry 40, 138-145.

Lubrano, M., Bauwens, L., Kirman, A., Protopopescu, C., 2003. Ranking European economic departments: A statistical approach. Journal of the European Economic Association 1, $1367-1401$.

Ulrich's Periodicals Directory, available online at http://www.ulrichsweb.com/ulrichsweb/ 
Table 1: Journal Information

\begin{tabular}{|l|l|l|l|}
\hline Journal name & ISSN & Started & Circulation \\
\hline American Journal of Economics and Sociology & $0002-9246$ & 1941 & 2200 \\
\hline Economic and Social Review & $0012-9984$ & 1969 & 450 \\
\hline Forum for Social Economics & $0736-0932$ & 1975 & 500 \\
\hline Humanomics & $0828-8666$ & 1984 & 150 \\
\hline International Journal of Social Economics & $0306-8293$ & 1974 & NA \\
\hline Journal of Economic and Social Policy & $1325-2224$ & 1995 & 130 \\
\hline Journal of Economic and Social Research & $1302-1060$ & 1999 & NA \\
\hline Journal of Economic Behavior \& Organization & $0167-2681$ & 1980 & NA \\
\hline Journal of Economic Psychology & $0167-4870$ & 1981 & NA \\
\hline Journal of Social and Economic Development & $0972-5792$ & 1998 & 150 \\
\hline Journal of Social, Political and Economic Studies & $0278-839 X$ & 1976 & 1100 \\
\hline Journal of Socio-Economics & $1053-5357$ & 1972 & 360 \\
\hline Mind \& Society & $1593-7879$ & 2000 & NA \\
\hline Rationality and Society & $1043-4631$ & 1989 & 750 \\
\hline Review of Social Economy & $0034-6764$ & 1948 & 2000 \\
\hline Society and Economy & $1588-9726$ & 1979 & NA \\
\hline Socio-Economic Review & $1475-1461$ & 2003 & NA \\
\hline
\end{tabular}


Table 2: Top 10 Economics Journals in JCR 2004

\begin{tabular}{|l|l|l|}
\hline Rank & Based on total citations received & Based on impact factor \\
\hline 1 & American Economic Review & Quarterly Journal of Economics \\
\hline 2 & Econometrica & Journal of Economic Literature \\
\hline 3 & Journal of Political Economy & Journal Economic Geography \\
\hline 4 & Quarterly Journal of Economics & Journal Economic Perspectives \\
\hline 5 & Journal of Financial Economics & Journal of Political Economy \\
\hline 6 & Journal of Econometrics & Journal of Financial Economics \\
\hline 7 & Review of Economics and Statistics & Journal of Health Economics \\
\hline 8 & Review of Economic Studies & Journal of Economic Growth \\
\hline 9 & Economic Journal & NBER Macroeconomics Annual \\
\hline 10 & Journal of Economic Theory & Economic Geography \\
\hline
\end{tabular}


Table 3: Rankings of Behavioral Economics and Socio-Economics Journals ${ }^{\text {a }}$

\begin{tabular}{|c|c|c|c|c|c|c|}
\hline Journal name & $\begin{array}{l}\text { Citing } \\
\text { articles } \\
2001- \\
2005\end{array}$ & $\begin{array}{l}\text { Rank } \\
2001- \\
2005\end{array}$ & $\begin{array}{l}\text { Citing } \\
\text { articles } \\
1996- \\
2000\end{array}$ & $\begin{array}{l}\text { Rank } \\
1996- \\
2000\end{array}$ & $\begin{array}{l}\text { Citing } \\
\text { articles } \\
1996- \\
2005\end{array}$ & $\begin{array}{l}\text { Rank } \\
1996- \\
2005\end{array}$ \\
\hline Journal of Economic Behavior \& Organization & 565 & 1 & 355 & 1 & 2258 & 1 \\
\hline Journal of Economic Psychology & 289 & 2 & 147 & 2 & 994 & 2 \\
\hline Journal of Socio-Economics & 108 & 3 & 56 & 6 & 393 & 5 \\
\hline American Journal of Economics and Sociology & 93 & 4.5 & 93 & 4 & 457 & 4 \\
\hline Rationality and Society & 93 & 4.5 & 144 & 3 & 561 & 3 \\
\hline Review of Social Economy & 41 & 6 & 60 & 5 & 273 & 6 \\
\hline International Journal of Social Economics & 39 & 7 & 36 & 7 & 220 & 7 \\
\hline Economic and Social Review & 19 & 8 & 34 & 8 & 136 & 8 \\
\hline Mind \& Society & 12 & 9 & 0 & & 26 & 9 \\
\hline Socio-Economic Review & $11^{\mathrm{b}}$ & 10 & 0 & & 11 & 11 \\
\hline Forum for Social Economics & 5 & 12 & 2 & 10 & 8 & 12.5 \\
\hline Journal of Economic and Social Policy & 5 & 12 & 3 & 9 & 16 & 10 \\
\hline Journal of Economic and Social Research & 5 & 12 & 0 & 15 & 7 & 14.5 \\
\hline Journal of Social, Political and Economic Studies & 2 & 14 & 1 & 12.5 & 5 & 16 \\
\hline Society and Economy & 1 & 15.5 & 1 & 12.5 & 7 & 14.5 \\
\hline Humanomics & 1 & 15.5 & 1 & 12.5 & 3 & 17 \\
\hline Journal of Social and Economic Development & 0 & 17 & 1 & 12.5 & 8 & 12.5 \\
\hline
\end{tabular}

The numbers in the "Citing articles" columns denote the number of articles that cited the journal in that period. For example, the number 565 in the column 2001-2005 corresponding to the Journal of Economic Behavior \& Organization (JEBO) implies that 565 articles that 
appeared in journals indexed by ISI cited during the period 2001-2005 articles that appeared in $J E B O$ during the same period.

${ }^{a}$ The reader should be careful when interpreting the results for journals that did not exist for the entire period; these include Mind \& Society (started in 2000), Socio-Economic Review (started in 2003), Journal of Economic and Social Research (started in 1999), and Journal of Social and Economic Development (started in 1998).

${ }^{\mathrm{b}}$ It is possible to get a better approximation for the relative quality of Socio-Economic Review in the 2001-2005 period in the following way. The journal started to be published in 2003, so the articles that cited it all come from the period 2003-2005. A few additional searches in the database reveal that 350 articles cited Journal of Economic Behavior and Organization, Journal of Economic Psychology, and Journal of Socio-Economics during 2003-2005, compared with 964 articles that cited these journals during the period 2001-2005 (the reason the number for 2001-2005 is much higher is that articles from 2001-2002 have more time to be cited than articles published in 2003-2005 when we consider citations from the period 2001-2005). We can apply the ratio $964 / 350=2.75$ to obtain that Socio-Economic Review achievement of 11 citations in $2003-2005$ is roughly equivalent to $30=2.75 * 11$ citations for the period 2001-2005, raising Socio-Economic Review to the $8^{\text {th }}$ rank. 
Table 4: A Comparison to Journals in Other Fields

\begin{tabular}{|c|c|}
\hline Journal name & $\begin{array}{l}\text { Citing articles } \\
2001-2005^{a}\end{array}$ \\
\hline \multicolumn{2}{|l|}{ Economics journals } \\
\hline Quarterly Journal of Economics & 1758 \\
\hline Econometrica & 1579 \\
\hline Rand Journal of Economics & 519 \\
\hline International Economic Review & 478 \\
\hline Economic Inquiry & 291 \\
\hline Journal of Industrial Economics & 276 \\
\hline Southern Economic Journal & 204 \\
\hline Kyklos & 121 \\
\hline Experimental Economics & 84 \\
\hline \multicolumn{2}{|l|}{ Psychology, marketing, and consumer behavior journals } \\
\hline Journal of Consumer Research & 776 \\
\hline Organizational Behavior and Human Decision Processes & 657 \\
\hline Marketing Science & 363 \\
\hline Journal of Consumer Psychology & 291 \\
\hline Psychology and Marketing & 281 \\
\hline Journal of Behavioral Decision Making & 212 \\
\hline \multicolumn{2}{|l|}{ Sociology journals } \\
\hline American Journal of Sociology & 848 \\
\hline Annals of Tourism Research & 234 \\
\hline Sociological Review & 190 \\
\hline Journal of Leisure Research & 130 \\
\hline Sociological Quarterly & 129 \\
\hline
\end{tabular}

${ }^{\text {a }}$ See the explanation in the comments for Table 3. 